\title{
Analisis Status Gizi Baduta (0-2 tahun) Di Provinsi Kepulauan Bangka Belitung Berdasarkan e-PPGBM Agustus 2020
}

\author{
Wiwin Efrizal ${ }^{1} *$ \\ ${ }^{1}$ Dinas Kesehatan Provinsi Kepulauan Bangka Belitung \\ Email : wiwinefrizal@gmail.com \\ Tanggal Submisi : 04 November 2020; Tanggal Penerimaan : 27 Februari 2021
}

\begin{abstract}
ABSTRAK
Periode usia $0-2$ tahun (Baduta) merupakan masa yang paling penting dalam tumbuh kembang manusia dan gangguan yang terjadi dalam masa tersebut dapat berdampak menetap. Pemantauan pertumbuhan dilakukan untuk memonitor masalah gizi yang terjadi secara dini dan menentukan penanganan yang tepat. Informasi tentang status gizi Baduta dalam Sistem Pencatatan dan Pelaporan Gizi Berbasis Masyarakat secara elektronik (ePPGBM) dapat dimanfaatkan dalam perencanaan kegiatan dan evaluasi kinerja serta intervensi gizi. Penelitian bertujuan untuk mengetahui gambaran status gizi bayi dan anak usia kurang dari dua tahun (Baduta) di Provinsi Kepulauan Bangka Belitung. Metode yang digunakan adalah penelitian kuantitatif dengan data sekunder status gizi Baduta Bangka Belitung yang diperoleh dari e-PPGBM Agustus 2020. Data dianalisa menggunakan metode statistik deskriptif dan metode grafik. Hasil penelitian didapatkan pemantauan pertumbuhan lebih banyak dilakukan oleh Baduta laki-laki dengan rasio menurut jenis kelamin yang membandingkan jumlah laki-laki dan perempuan sebesar 117,4 dan hanya 13,2\% Baduta yang naik berat badannya berdasarkan grafik KMS. Kekurangan gizi menurut indikator $\mathrm{BB} / \mathrm{U}$ dialami Baduta sebanyak 4,3\% dengan rentang per kabupaten/kota sebesar 1,7 10,5\% dan kelebihan gizi terjadi pada 7,1\% dengan rentang 5,1 - 9,5\%. Prevalensi Baduta stunting di Bangka Belitung sebesar 4,3\% dengan rentang besaran menurut Kabupaten/Kota berkisar 1,6 - 9,7\% dan Baduta wasting sebanyak 2,1\% dengan rentang per Kabupaten/Kota berkisar $0,7-5,3 \%$. Kesimpulan penelitian yaitu proporsi Baduta yang naik berat badannya masih sangat rendah dan masih terdapat perbedaan yang besar terkait hasil prevalensi status gizi Baduta menurut e-PPGBM dengan hasil Riskesdas 2018 dan SSGBI 2019.
\end{abstract}

Kata kunci : anak Baduta, status gizi

\begin{abstract}
The 0-2 year age period (Baduta) is the most important period in human development and the disturbances that occur during this period can have a permanent effect. Growth monitoring is carried out to monitor nutritional problems that occur early and determine the appropriate treatment. Information on the nutritional status of Baduta in the electronic Community-Based Nutrition Recording and Reporting System (e-PPGBM) can be used in planning activities and performance evaluation as well as nutrition interventions. This study aims to know the description of the nutritional status of infants and children aged less than two years (Baduta) in the Province of Bangka Belitung Islands. The method used quantitative research with secondary data on nutritional status of Baduta Bangka Belitung obtained from the August 2020 e-PPGBM. Data were analyzed using descriptive statistical methods and graphical methods. The results showed that growth monitoring was mostly done by male Baduta with a ratio according to sex comparing the number of males and females of 117.4 and only $13.2 \%$ of Baduta gained weight based on the KMS chart. Malnutrition according to the indicator of weight / age experienced by Baduta is as much as $4.3 \%$ with a range per district / city of $1.7-10.5 \%$ and excess nutrition occurs at $7.1 \%$ with a range of $5.1-9.5 \%$. The prevalence of stunting Baduta in Bangka Belitung is $4.3 \%$, with a
\end{abstract}


range of numbers according to Regency / City ranging from 1.6 to $9.7 \%$ and Baduta wasting as much as $2.1 \%$ with a range per Regency / City ranging from 0.7 to $5.3 \%$. The conclusion of the study is proportion of Baduta gaining weight is still very low and there is still a big difference regarding the results of the prevalence of Baduta nutritional status according to ePPGBM with the results of Riskesdas 2018 and SSGBI 2019.

Keywords : Baduta children, nutritional status

ISSN 1979-7621 (Print). ISSN 2620-7761 (Online).

DOI : $10.23917 / j k . v 14 i 1.12331$

\section{Pendahuluan}

Masa balita merupakan periode yang penting dalam pertumbuhan danperkembangan manusia. Pada periode ini, berbagai perkembangan dalam kemampuan penggunaaan bahasa, timbulnya kreativitas, adanya kesadaran sosial, emosional, dan intelegensia berjalan dengan sangat cepat dan menjadi landasan untuk perkembangan berikutnya. Pada masa kehidupan awal umur 0-2 tahun menjadi masa yang paling rawan, karena terjadinya gangguan dalam masa tersebut akanmenimbulkan efek yang menetap. Pada periode 2 tahun pertama setelah kelahiran ini terjadi perkembangan saraf otak yang cepat, terutama mielinisasi dengan kecepatan pertumbuhan yang mencapai puncak dalam 2 kali periode, yaitu pada masa kehamilan minggu ke 1520 dan usia kehamilan minggu ke 30 sampai anak berusia 18 bulan(Diana, 2010).

Kesehatan anak membutuhkan perhatian, karena mereka merupakan kelompok rawan untuk mengalami masalah kesehatan dan kematian serta berdampak besar pada generasi penerus bangsa. Salah satu upaya pemantauan kondisi gizi dan kesehatan dilakukan dalam bentuk pemantauan pertumbuhan balita yang dilaksanakan di posyandu(Aditianti, 2019).

Pemantauan pertumbuhan padaBalita perlu dilakukan sebagai bagian dari standar pelayanan minimal (SPM) yang harus dilakukan di seluruh daerah. Data terkait status gizi masyarakat menjadi kebutuhan untuk mengetahui besaran masalah gizi yang ada dalam wilayah tertentu sebagai dasar perencanaan dan pelaksanaan kegiatan, termasuk intervensi apa yang akan dilakukan para pemangku kepentingan serta evaluasi kinerja.

Sistem Gizi Terpadu atau Sigizi dikembangkanuntuk mempermudah pencatatan dan melaporkan data gizi, yang meliputi data sasaran yang ada, status gizi individu yang diukur, cakupan kinerja program dan data Pemberian Makanan Tambahan (PMT) yang berasal dari berbagai sumber anggaran yang ada. Aplikasi Pencatatan dan Pelaporan Gizi Berbasis Masyarakat atau yang disebut ePPGBM menjadi bagian dari Sigizi Terpadu yang dikembangkan untuk mempermudah dalam melakukan pencatatan data sasaran individu dan kegiatan penimbangan atau pengukuran berat badan serta tinggi badan Balita yang dapat diharapkan dapat memberikan umpan balik secara langsung status gizi sasaran tersebut(Direktorat Gizi Masyarakat, 2017).

Tujuan penelitian ini adalah mengetahui gambaran status gizi bayi dan anak usia kurang dari dua tahun (Baduta) di Provinsi Kepulauan Bangka Belitung.

\section{Metode}

Penelitian kuantitatif ini menggunakan data status gizi anak usia 0-2 tahun dalam wilayah Provinsi Kepulauan Bangka Belitung bulan Agustus 2020. Data tersebut merupakan data sekunder yang diperoleh dari Sistem Pencatatan dan Pelaporan Gizi Berbasis 
Masyarakat secara elektronik (e-PPGBM) yang dikembangkan oleh Direktorat Gizi Masyarakat Kementerian Kesehatan RI. Analisa data menggunakan metode statistik deskriptif dan metode grafik.

\section{Hasil}

\section{Karakteristik Sampel}

Pada Agustus 2020 terukur berat badan dan tinggi badan pada 39.046 orang Baduta. Sebagian besar Baduta yang diukur berjenis kelamin laki-laki dengan rasio menurut jenis kelamin dengan membandingkan jumlah Baduta laki-laki dengan perempuan sebesar 117,4 dan pada setiap Kabupaten/Kota berkisar 108,8127,9. Jumlah Baduta yang dipantau pertumbuhannya pada Agustus 2020 disajikan gambar 1.

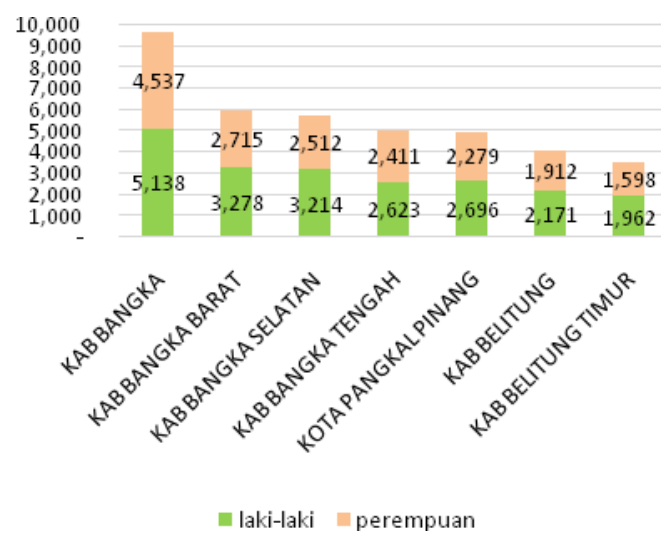

Gambar 1. Proporsi Baduta menurut Jenis Kelamin

Baduta yang naik berat badannya dalam kegiatan pemantauan pertumbuhan pada Agustus 2020 masih sangat rendah sebagaimana disajikan pada gambar 2 .

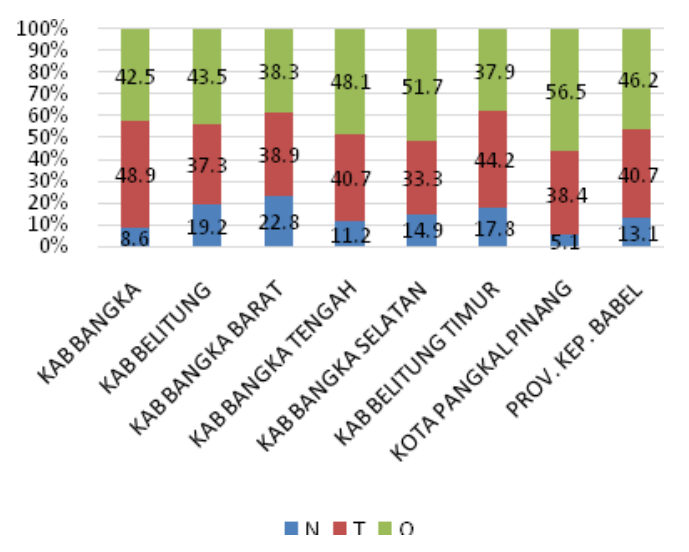

Gambar 2. Proporsi Baduta berdasarkan Status Pertumbuhannya

\section{Partisipasi Masyarakat dalam Pemantauan Pertumbuhan}

Partisipasi masyarakat dalam kegiatan pemantauan pertumbuhan pada kelompok Baduta sangat tinggi di seluruh Kabupaten/Kota yang ada dengan target $80 \%$ Baduta ditimbang berat badannya sebagaimana ditampilkan dalam gambar 2 .

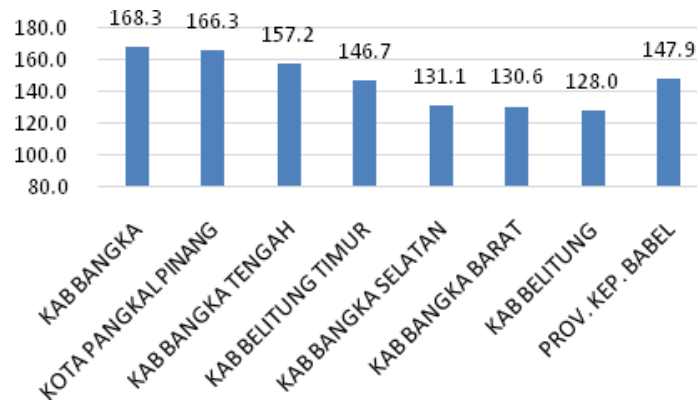

Gambar 2. Cakupan Partisipasi Masyarakat (D/S) dalam pemantauan pertumbuhan Baduta

Rata-rata posyandu yang ada di Bangka Belitung pada Agustus 2020 dikunjungi sebanyak 35 orang Baduta seperti tergambar pada gambar 3 .

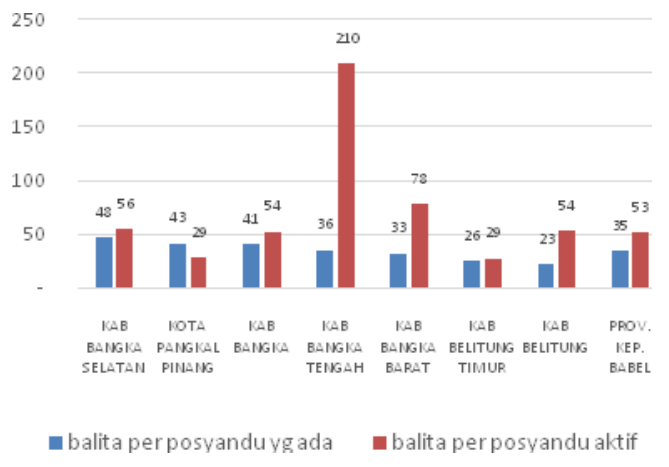

Gambar 3. Rata-rata Jumlah Baduta per posyandu menurut Kabupaten/Kota

\section{Karakteristik Sampel menurut Indikator $\mathrm{BB} / \mathrm{U}$}

Seluruh Kabupaten/Kota di Provinsi Kepulauan Bangka Belitung mempunyai Baduta dengan masalah gizi ganda sebagaimana ditampilkan pada gambar 3 . 


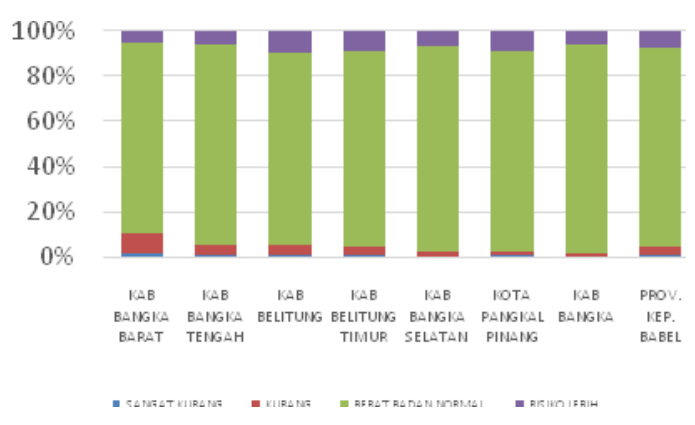

Gambar 3. Proporsi Status Gizi Baduta menurut Indikator BB/U

\section{Karakateristik Sampel menurut Indikator $\mathrm{TB} / \mathrm{U}$}

Masalah kekurangan gizi kronis terdapat di sebagian besar Kabupaten/Kota yang ada di Provinsi Kepulauan Bangka Belitung sebagaimana disajikan dalam gambar 4.

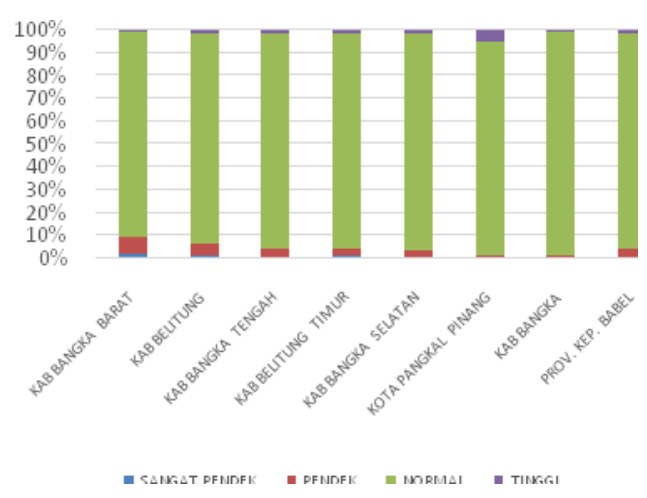

Gambar 4. Proporsi Status Gizi Baduta menurut Indikator TB/U

\section{Karakteristik Sampel menurut Indikator BB/TB

Sebagian besar sampel

mempunyai berat badan yang proporsional menurut tinggi badannya dan hanya 2,1\% Baduta yang mengalami kekurangan gizi serta 9,9\% Baduta mengalami kelebihan gizi. Gambaran status gizi menurut indikator $\mathrm{BB} / \mathrm{TB}$ dapat dilihat pada gambar 5.

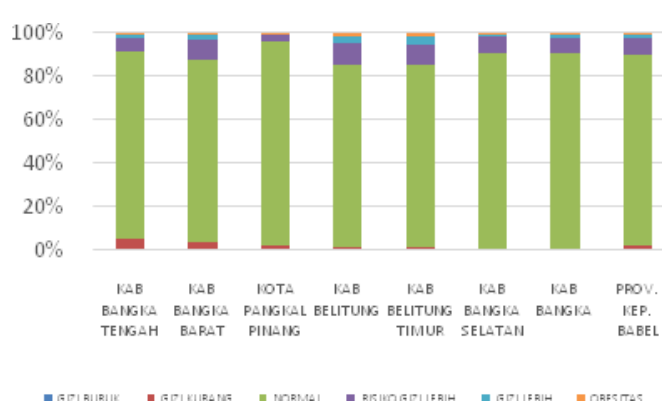

Gambar 5. Proporsi Status Gizi Baduta menurut Indikator BB/TB

\section{Pembahasan}

Pemantauan pertumbuhan menjadi kegiatan utama di Pos Pelayanan Terpadu (Posyandu) yang bertujuan untuk mengidentifikasi terjadinya perlambatan pertumbuhan atau kegagalan pertumbuhan pada tingkat individu, sehingga dapat diantisipasi dan diintervensi dengan tepat(Aditianti, 2019).Pemantauan pertumbuhan dilakukan di 1.104 posyandu yang ada di Bangka Belitung, namun hanya 740 posyandu yang aktif melaksanakan kegiatan bulanan pada periode triwulan II 2020. Kondisi ini menunjukkan posyandu belum dimanfaatkan secara optimal sebagai upaya pelayanan kesehatan yang diselenggarakan oleh masyarakat untuk masyarakat dengan dukungan teknis dari petugas kesehatan setempat(Subagyo, 2015).

Hasil e-PPGBM Agustus 2020 menunjukan rata-rata Baduta yang berkunjung ke posyandu sebanyak 35 orang dan angka tersebut akan meningkat bila dilihat dari jumlah posyandu yang aktif saja. Setiap posyandu mempunyai sasaran 50-100 orang Balita, namun dapat disesuaikan dengan kondisi setempat. Jumlah Baduta per posyandu aktif yang sangat tinggi di Kabupaten Bangka Tengah menunjukkan masih belum optimalnya posyandu yang ada, karena $82,9 \%$ posyandu yang ada tidak aktif melakukan kegiatan bulanan.

Motivasi ibu atau keluarga untuk membawa Baduta ke posyandu sangat tinggi, karena seluruh Kabupaten/Kota mempunyai cakupan partisipasi masyarakat di atas $100 \%$. Namun, kondisi ini diasumsikan terjadi karena adanya pencatatan ganda terhadap data identitas 
Baduta. Selain itu, tidak ditemukan adanya Baduta yang baru "B" di posyandu yang diasumsikan belum terdeteksinya data tersebut dalam e-PPGBM. Motivasi ibu atau keluarga dipengaruhi oleh tingkat pengetahuan ibu tentang posyandu, status pekerjaan ibu, dan adanya kebutuhan yang dirasakan untuk ibu dan Baduta seperti imunisasi gratis, mengetahui pertumbuhan dan perkembangan anaknya, atau ingin mendapatkan bantuan(Puspitasari, 2015).Kader posyandu mempunyai peran penting dalam mendukung motivasi ibu Baduta untuk berkunjung ke posyandu(Subagyo, 2015).

Baduta laki-laki lebih banyak berkunjung ke posyandu bila dibandingkan dengan Baduta perempuan. Rasio jenis kelamin sebesar 117,4 dan pada setiap Kabupaten/Kota berkisar 108,8-127,9. Kondisi ini sesuai dengan sex ratiopenduduk Bangka Belitung sebesar 108(Puspitasari, 2015).Tingginya rasio jenis kelamin kunjungan ke posyandu diasumsikan juga dipengaruhi oleh pola asuh, danadanya anggapan anak laki-laki lebih kuat dibanding anak perempuan, sehingga anak perempuan lebih mendapatkan perhatian daripada lakilaki(Sofiani, 2020). Selain itu, ada kebiasaan di daerah tertentu untuk tidak membawa anaknya ke luar rumah sebelum berusia 2-3 bulan.

Penilaian pertumbuhan Baduta dapat dilakukan dengan cara menimbang berat badannya secara teratur di posyandu atau tempat lainnya(Danik, 2017). Kegiatan pemantauan pertumbuhan di posyandu merupakan pencegahan gizi kurang dan peningkatan perilaku/pola asuh ibu(Nurcahyani, 2015).Pola asuh adalah suatu sikap dan praktek yang dilakukan oleh orang tua/keluarga dalam memberikan makan pada anak, memberikan stimulasi, memberikan kasih sayang agar anak dapat tumbuh kembang dengan baik(Sofiani, 2020).

Pola asuh yang baik berdampak pada peningkatan berat badan anak. Perubahan berat badan merupakan indikator yang mudah digunakan untuk memantau pertumbuhan anak dengan cara mengisikan berat badan ke Kartu Menuju Sehat (KMS) dan diketahui status
pertumbuhannya(Danik, 2017).Baduta yang naik berat badannya pada penimbangan Agustus 2020 sebesar 13,2\% yang sangat sedikit bila dibandingkan dengan tujuan Upaya Perbaikan Gizi Keluarga (UPGK) di posyandu agar semua Baduta naik berat badannya(Kemenkes, 2011).Kondisi ini akan meningkatkan risiko terjadinya kurang gizi pada Baduta.

Kenaikan berat badan Baduta yang sesuai dengan grafik pertumbuhan dalam KMS dipengaruhi oleh asupan makanan dan paparan infeksi (Sudiana, 2007).Baduta yang mengalami kegagalan pertumbuhan dengan status pertumbuhan "tidak naik berat badannya (T)" sebesar 41,1\% dan/atau "tidak ditimbang bulan lalu (O)" sebesar $45,7 \%$ di Bangka Belitung dapat meningkatkan risiko terjadinya kekurangan gizi.

Ketidak-teraturan penimbangan berat badan Baduta yang tercermin dari besaran status pertumbuhan "O" menunjukkan pemahaman ibu dan keluarga untuk menimbang berat badan anaknya masih kurang. Alasan ibu atau keluarga untuk tidak membawa anaknya ke posyandu antara lain balita sakit, ibu sedang sibuk, ibu tersinggung karena anaknya dikatakan gizi buruk atau perkataan negatif lainnya, anak rewel atau menangis setiap ditimbang sehingga ibu menjadi kasihan dan malas datang ke posyandu, anak sedang tidur atau sedang mengikuti kegiatan lain atau tidak ada di rumah, serta alasan jarak dari rumah ke posyandu(Nurcahyani, 2015).

Baduta yang ditimbang pada Agustus 2020 sebagian besar mempunyai status gizi kategori normal menurut indikator $\mathrm{BB} / \mathrm{U}$. Baduta yang mengalami kekurangan gizi sebanyak 4,3\% dengan rentang per kabupaten/kota sebesar 1,7$10,5 \%$ dan kelebihan gizi terjadi pada 7,1\% dengan rentang 5,1-9,5\%. Kondisi ini memberikan gambaran, kemungkinan terjadinya masalah gizi ganda yang disebabkan kekurangan gizi yang masih ada dan kelebihan gizi yang semakin meningkat.

Penggunaan indikator BB/U untuk menunjukkan status gizi saat ini (current nutrition). Namun, parameter yang digunakan sangat labil dan mudah 
mengalami kenaikan atau penurunan, karena dipengaruhi oleh faktor asupan makanan atau infeksi yang terjadi(handayani, 2012). (Nurrizky, 2018). Anak yang sehat akan mengalami kenaikan berat badan seiring dengan pertambahan umurnya(Kemenkes, 2012).Berat badan digunakan sebagai alat monitor pertumbuhan anak, sehingga masalah dapat diketahui lebih awal guna dilakukan pencegahan dan penanganan yang tepat(Wahyuni, 2016).

Pada masa Baduta terdapat periode transisi dari masa bayi yang mengkonsumsi Air Susu Ibu (ASI) beralih ke makanan padat dengan jenis yang beragam. Pemberian Makanan Tambahan sering menjadi strategi dalam mengatasi masalah gizi. Namun tingkat keberhasilannya masih belum optimal disebabkan sebagian besar orang tua belum memahami cara pemberian PMT yang tepat(Kurniasih, 2018). Selain itu, adanya penurunan napsu makan anak yang disebabkan infeksi, anak mulai aktif berinteraksi dengan lingkungannya, kebiasaan jajan serta kurangnya variasi dalam pemberian makan menjadi faktor yang turut mengurangi keberhasilan pemberian makan pada anak(Imas Rini, 2017).

Pemberian gizi yang baik pada 1000 hari pertama kehidupan (HPK) dimulai dari 270 hari selama kehamilan dan 730 hari pasca lahir dapat menentukan kualitas hidup anak. Pemberian makan pada Baduta dipengaruhi oleh budaya dan tradisi, pengalaman ibu, tuntutan keluarga, dan keadaan sosial ekonomi(Sofiyanti, 2017). Pendidikan gizi dalam cara pembuatan dan pemberian makan bagi bayi dan anak (PMBA) dapat dijadikan salah satu intervensi untuk meningkatkan status gizi pada anak dan menurunkan risiko stunting(Kumala, 2019).

Stunting merupakan indeks tinggi badan menurut umur minus dua standar deviasi berdasarkan standar Badan Kesehatan Dunia (WHO) yang merupakan dampak dari kekurangan gizi selama 1000 HPK(Setiawan, 2018). Baduta stunting di Bangka Belitung berdasarkan e-PPGBM Agustus 2020 sebesar 4,3\% dengan rentang besaran menurut Kabupaten/Kota berkisar
1,6-9,7\%. Kondisi ini menunjukkan masalah stunting tidak lagi menjadi masalah kesehatan masyarakat di Provinsi Kepulauan Bangka Belitung. Namun Riset Kesehatan Dasar (Riskesdas) 2018 menunjukkan prevalensi stuntingdi Bangka Belitung sebesar 23,28\% dan hasil Studi Status Gizi Balita Terintegrasi (SSGBI) Susenas 2019 menunjukkan telah terjadi penurunan 3,35\% menjadi 19,93\%(Puslitbangkes, 2019) (Izwardy, 2019).

Keadaan stunting dipengaruhi oleh status pemberian ASI eksklusif, kualitas dan kecukupan asupan gizi makanan pendamping ASI (MP-ASI), dan status kesehatan bayi(Puslitbangkes, 2019).Pengetahuan ibu yang kurang, pola asuh yang salah, sanitasi dan kesehatan perorangan yang buruk dan rendahnya pelayanan kesehatan turut menjadi faktor yang menyebabkan terjadinya stunting. Selain itu, pemahaman ibu dan keluarga terhadap kondisi anak pendek merupakan suatu masalah masih rendah, sehingga penanggulangan dini jarang dilakukan apabila aktivitas anak masih normal(Mitra, 2015).

Indikator antropometri yang mengindikasikan terjadinya wasting adalahberat badan menurut tinggi badan (BB/TB)(Aisyah, 2019).Status gizi Baduta berdasarkan indikator tersebut di Bangka Belitung menunjukkan prevalensi wasting sebesar 2,1\% dengan rentang per Kabupaten/Kota berkisar 0,7-5,3\%, sedangkan kelebihan gizi terjadi pada 9,9\% Baduta dengan rentang per Kabupaten/Kota berkisar 3,7-14,8\%. Kondisi wasting ini dianggap masalah kesehatan masyarakat kategori tidak serius, karena prevalensi di bawah 10\%(Rochmawati, 2018).

Wasting menggambarkan keadaan kekurangan gizi dimana berat badan Balita tidak sesuai dengan tinggi badan, sehingga terlihat kurus, yang berakibat terganggunya pertumbuhan fisik dan kecerdasan anak. Konsumsi makanan yang kurang dan infeksi menjadi dua faktor yang saling mempengaruhi kejadian wasting. Pemberian ASI eksklusif dapat meningkatkan imunitas tubuh anak yang berdampak pada rendahnya gangguan 
pertumbuhan dan munculnya penyakit infeksi(Aisyah, 2019) (Afriyani, 2016).

Riskesdas 2018 menunjukkan hanya $69,53 \%$ bayi $0-5$ bulan di Bangka Belitung yang mendapatkan ASI eksklusif dan sebanyak $80,8 \%$ ibu telah memberikan seluruh kolostrum kepada bayinya. Baduta yang masih menyusu hingga usia 24 bulan sebanyak 50,12\% dan alasan tidak menyusui selain alasan medis adalah ASI tidak keluar, anak tidak bisa menyusu, repot, riwayat pisah, anak terpisah dari ibu dan alasan lainnya(Puslitbangkes, 2019).

Pengetahuan terkait gizi pada ibu dapat mengoptimalkan status gizi anak, karena ibu dapat memberikan pengasuhan yang tepat, termasuk pemberian makanan yang bergizi, beragam dan berimbang pada bayi dan anaknya. Pengetahuan ibu yang baik harus diimbangi dengan dengan sikap, kemampuan, serta kepercayaan diri dalam mengurus anaknya(Aisyah, 2019).

\section{Kesimpulan}

1. Motivasi ibu atau keluarga untuk membawa Baduta ke posyandu telah baik.

2. Proporsi Baduta yang naik berat badannya berdasarkan penimbangan di posyandu masih sangat rendah yang dapat meningkatkan risiko masalah gizi.

3. Masih terdapat perbedaan yang besar terkait hasil prevalensi status gizi
Baduta menurut e-PPGBM dengan hasil Riskesdas 2018 dan SSGBI 2019.

4. Masalah gizi ganda pada Baduta di Bangka Belitung masih dapat terjadi, karena masih rendahnya pemahaman ibu dan keluarga dalam pemberian makan pada bayi dan anak (PMBA).

\section{Saran}

1. Perlunya validasi data e-PPGBM, sehingga dapat memberikan gambaran lebih valid terkait status gizi Baduta di Bangka Belitung.

2. Perlunya motivasi dan peningkatan pemahaman ibu terkait pemantauan pertumbuhan pada Baduta, baik di posyandu maupun mandiri.

3. Perlunya peningkatan pemahaman ibu dan keluarga dalam pemberian makan pada bayi dan anak (PMBA)

\section{Ucapan Terima Kasih}

Peneliti mengucapkan puji syukur ke hadirat Allah SWT yang telah melimpahkan rahmat dan hidayah-Nya dan ucapan terima kasih kepada Kepala Dinas Kesehatan Provinsi Kepulauan Bangka Belitung yang telah memberikan dukungan dalam pelaksanaan penelitian ini serta kepada keluarga Peneliti yang telah memberikan dukungan moral agar Peneliti dapat terus berkarya.

\section{DAFTAR PUSTAKA}

Aditianti, A., Luciasari, E., Permanasari, Y., Julianti, ED., Permana, M. (2019). Studi Kualitatif Pelaksanaan Pemantauan Pertumbuhan Anak Balita Di Posyandu Di Kabupaten Bandung. Penelit Gizi dan Makanan (The J Nutr Food Res)

Afriyani, R., Malahayati, N., Hartati, H. (2016). Faktor-faktor yang MempengaruhiKejadian Wasting pada Balita Usia 1-5Tahun di Puskesmas Talang Betutu KotaPalembang. J Kesehat.

Nurrizky, Ahmad. (2018). PerbandinganAntropometri GiziBerdasarkan BB/U, TB/U, DanIMT/U Siswa SD Kelas BawahAntara Dataran Tinggi DanDataran Rendah Di KabupatenProbolinggo. J Pendidik Olahraga danKesehat [Internet]. 2018;06(01):17581. darihttp://jurnalmahasiswa.unesa.ac.id/index.php/jurnal-pendidikanjasmani/article/download/22920/15976

Aisyah, Nanda., Amirah, MAR. (2019). Karakteristik,Pengetahuan Gizi Ibu dan Status GiziBalita (BB/TB) Usia 6-59 bulan. AmertaNutr [Internet]. 2019;189-93. Dari : 
https://e-journal.unair.ac.id/AMNT/article/download/14067/8207

Danik, R., Hanifah, L. (2017). Evaluasi Pertumbuhan Balita Berdasarkan Umur Dan Berat Badan [Internet]. Surakarta. Dari : https://jurnal.stikesmus.ac.id/index.php/JK ebIn/article/download/18/17

Diana, FM. (2010). PemantauanPerkembanganAnakBalita. J Kesehat Masy.

Direktorat Gizi Masyarakat. (2017). Buku Panduan Pencatatan dan Pelaporan Gizi Berbasis Masyarakat(e-PPGBM) Offline Sistem Informasi Gizi Terpadu [Internet]. Jakarta: Kementerian Kesehatan Republik Indonesia. Dari : https://sigiziterpadu.gizi.kemkes.go.id/sso/ppgbmoff/panduan_ppgbmoffline_v2.pdf

Sudiana, I.K., Yuni, SA.(2007). Peningkatan Berat Badan PadaBayi (3-6 Bulan) Melalui InfantExercise [Internet]. Surabaya. Dari : $\underline{\text { https://e- }}$ journal.unair.ac.id/JNERS/article/download/4960/3202

Sofiyanti, I., Melisa,NR. (2019). SosialisasiPraktek Pemberian Makan bagi Anak(PMBA) pada Kader Posyandu Desa SiwalKecamatan Kaliwungu KabupatenSemarang. Indones $\mathrm{J} \quad$ CommunityEmpower [Internet]. Dari :http://jurnal.unw.ac.id:1254/index.php/IJC E/article/download/322/277

Rini, I.,Pangestuti, DR. (2017). Pengaruh PemberianMakanan TambahanPemulihan (PMTP) TerhadapPerubahan Status Gizi BalitaGizi Buruk Tahun 2017 (Studi diRumah Gizi Kota Semarang). J KesehatMasy [Internet]. 2017;5(4). Dari :https://ejournal3.undip.ac.id/index.php/jkm/article/viewFile/18753/17831

Izwardy, D. (2020). Presentasi Studi Status GiziBalita Terintegrasi Susenas 2019 [Internet].Jakarta.Dari :https://www.kemkes.go.id/resources/download/infoterkini/Rakerkesnas-2020/02-Sideevent/SE_08/StudiStatusGiziBalitaTerintegrasiSUSENAS2019KapusLitbangUKM.pd $\mathrm{f}$

Kementerian Kesehatan RepublikIndonesia. (2011). Buku Panduan Kader PosyanduMenuju Keluarga Sadar Gizi. Jakarta:Kementerian Kesehatan RepublikIndonesia.

Kementerian Kesehatan RI. (2012). Buku SakuAyo ke Posyandu Setiap Bulan.Kementrian Kesehatan RI, Pusat PromosiKesehatan.

Kumala, D., Sianipar, SS. (2019). PengaruhPemberian Makanan Bayi Dan Anak(PMBA) Sesuai Tahapan Pada Balita Usia0 - 24 Bulan Dalam Upaya PenurunanResiko Stunting Pada 1000 Hari PertamaKehidupan Di Posyandu Wilayah KerjaPuskesmas Kereng Bangkirai KotaPalangka Raya Kalimantan Tengah. DinKesehat J KEBIDANAN DANKEPERAWATAN.

Kurniasih, E., Prawoto, E,, Pariyem, P. (2018). Upaya Peningkatan Gizi BalitaDengan Pemberian MakananTambahan (PMT) Berkualitas DiDesa Pangkur, Kec.Pangkur,Kabupaten Ngawi. J Pengabdi MasyKesehat.

Mitra, M. (2015). Permasalahan Anak Pendek(Stunting) dan Intervensi untuk MencegahTerjadinya Stunting (Suatu KajianKepustakaan). J Kesehat Komunitas. 
Nurcahyani, L., Hakimi, M,, Sudargo, T. (2015). Efek Pemanfaatan ProgramPemantauan Dan PromosiPertumbuhan Terhadap StatusGizi Balita Di Kota Cirebon. JKesehat Reproduksi.

Puslitbangkes. (2019). Laporan ProvinsiKepulauan Bangka Belitung Riskesdas2018 [Internet]. Jakarta. Dari :https://ejournal2.litbang.kemkes.go.id/index.php/lpb/article/view/3784

Puspitasari, I. (2015). Faktor - Faktor Yang Mempengaruhi Partisipasi Ibu Balita Ke Posyandu Kencursari I Di Dukuh Tegaltandan Desa Banguntapan Kabupaten Bantul [Internet]. Sekolah Tinggi Ilmu Kesehatan "Aisyiyah Yogyakarta. Dari : https://core.ac.uk/download/pdf/29943366.pdf

Rochmawati, R., Marleny, W., Waliyo E. (2016). GiziKurus (Wasting) Pada Balita Di WilayahKerja Puskesmas Kota Pontianak. VokasiKesehat.

Setiawan, E., Machmud, R., Masrul, M. (2018). Faktor-Faktor yang Berhubungan denganKejadian Stunting pada Anak Usia 24-59Bulan di Wilayah Kerja PuskesmasAndalas Kecamatan Padang Timur KotaPadang Tahun 2018. J Kesehat Andalas.

Handayani, S., Yatmihatun,SH. (2012). Perbandingan Status GiziBalita Berdasarkan IndexsAntropometri BB/U Dan BB/TBPada Posyandu Di WilayahBinaan Poltekkes Surakarta. JTerpadu Ilmu Kesehat [Internet]. 2012;2:1-94. Dari :https://core.ac.uk/download/pdf/296611907.pdf

Sofiani, IK., Mufika, T., Mufaro'ah, M. (2020). Bias Gender dalam Pola Asuh Orangtua pada Anak Usia Dini. J Obs J Pendidik Anak Usia Dini.

Subagyo, W., Wahyuningsih, D., Mukhadiono, M. (2015). Peran kader dalam memotivasi ibu balita berkunjung ke posyandu. Soedirman J Nurs.

Wahyuni, S., Wahyuningsih, A. (2016). Pemberian Makan Pada Bayi dan Anak dengan Kenaikan Berat Badan Bayi di Kabupaten Klaten. Rakernas Aipkema. 